\title{
latrogenic Rectal Diverticulum After Stapled Transanal Rectal Resection
}

\author{
Bin Zhang ${ }^{\mathrm{a}}$, Jian Hua Ding ${ }^{\mathrm{a}}$, Meng Zhang ${ }^{\mathrm{b}}$, Shu Hui Yin ${ }^{\mathrm{a}}$, Yu Juan Zhao ${ }^{\mathrm{a}}$, Ke Zhao ${ }^{\mathrm{a}, \mathrm{c}}$
}

\begin{abstract}
Iatrogenic rectal diverticulum is an unexpected complication after stapled transanal rectal resection. We herein report a case of a female patient presented with severe recurrence of obstructed defecation after the surgery for obstructed defecation syndrome. Notably, an isolated rectal wall diverticulum with impacted fecalith was confirmed at 34-months follow-up. The patient experienced progressive improvement after operative reintervention. Therefore, risk of rectal diverticulum following the procedure should not be underestimated.
\end{abstract}

Keywords: Rectal diverticulum; Stapled transanal rectal resection; Obstructed defecation syndrome

\section{Introduction}

Stapled transanal rectal resection (STARR) has been advocated for the treatment of obstructed defecation syndrome (ODS) associated with symptomatic rectocele and intussusception. Although initial reports confirmed the effectiveness and safety of the novel technique [1-4], serious complications have nevertheless been described [5]. Herein, we report an unusual case of a huge rectal diverticulum with impacted fecalith developed after STARR surgery, followed by a review of the relevant literature.

\footnotetext{
Manuscript accepted for publication May 10, 2012

${ }^{a}$ Department Department of Colo-Rectal Disease Surgery, The Second Artillary General Hospital, Beijing 100088, China

${ }^{b}$ Department of Medicine, The Second Artillary General hospital, Beijing 100088, China

${ }^{\mathrm{c}}$ Corresponding author: Ke Zhao, Department of Colo-Rectal Disease Surgery, The Second Artillary General Hospital, No.16 Xinjiekouwai Road, Xicheng District, 100088, Beijing, China.

Email: thalarus@yahoo.cn
}

doi:http://dx.doi.org/10.4021/jmc695w

\section{Case Report}

A 55-year-old female was admitted because of a 5-year history of obstructed defecation. The patient presented with a sensation of incomplete evacuation requiring enemas and digital assistance. Moreover, she had been medically treated with diet ( $1.5 \mathrm{~L} / \mathrm{d}$ of water, high fiber diet), laxatives $(10 \mathrm{~g} / \mathrm{d}$ of lactulose) and physiotherapy for 12 months with no results. Defecography confirmed the diagnosis of third-degree rectocele and second-degree intussusception. Anorectal manometry revealed increased threshold and maximum tolerated volumes. Additionally, there were no underlying contraindications for STARR in accordance with the consensus statement published by Pioneers group [6]. The operation was performed according to recommendations for the performance of STARR [1], and the patient was discharged on the fourth postoperative day.

At 3-months follow-up, constipation improved and no obvious complications were found. The patient complained of recurrence of preoperative symptomatology with a worsing of obstructed defecation even though an intact staple ring was detected by digital rectal examination and endoscopy at 6-months. Intriguingly, a perirectal, rigid, painless mass was palpable at right lateral staple suture at 34-months after surgery. Computer tomography (Fig.1a) showed a $34 \mathrm{x}$ $23 \mathrm{~mm}$ lesion in the right supralevator space, communicated with rectal lumen at the level of the staple line. Colonoscopy (Fig.1b) confirmed an isolated diverticulum cavity of rectal wall without obvious inflammation. Then, transanal diverticulectomy was performed and an impacted fecalith was removed in the diverticulum cavity (Fig.1c). Neither staples nor abscess in the perirectal adipose tissue was found, and the rectal wall was directly reconstructioned. The pathologic examination (Fig.1d) showed a true diverticulum involving the entire rectal layer. The postoperative course was uneventful and the symptoms of defecation were significantly improved during 12-month follow-up.

\section{Discussion}

Rectal diverticulum disease is extremely rare with an inci- 


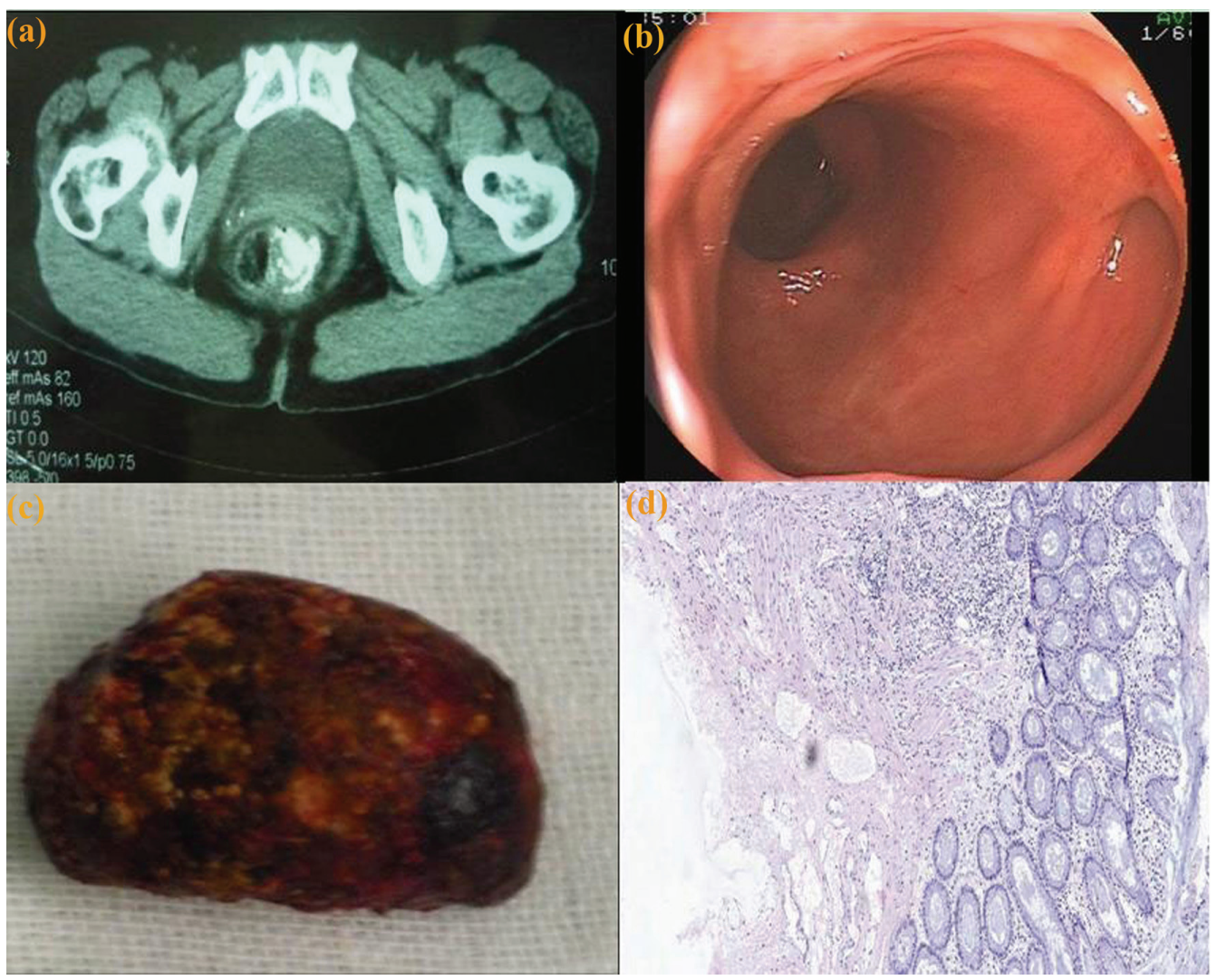

Figure 1. (a) Computer tomography: a $34 \times 23 \mathrm{~mm}$ lesion, in the right supralevator space, was identified. The lesion was communicated with rectal lumen at the level of the staple line. (b) Colonoscopy view: an isolated diverticulum cavity in the rectum. (c) Surgical specimen: an impacted fecalith in the rectal diverticulum cavity. (d) Histologic examination: the entire rectal layer with the mucosa, submucosa, and proper muscle (H and $\mathrm{E}$ stain, $\mathrm{x} 5$ ).

dence of $0.07-0.08 \%[7,8]$. The pathogenesis of this condition is still not completely understood. Some predisposing factors include congenital defects, constipation, recurring impaction, relaxed rectovaginal septum, infections, ulcerations and rectal trauma leading to weakening of the rectal wall [8-11]. Recently, the occasional development of iatrogenic rectal diverticulum following STARR procedure has been described by sporadic reports $[12,13]$.

Rectal diverticula are typically located along the lateral walls of the rectum [10]. Consistently, our case demonstrated that an isolated rectal diverticulum was actually located on the right lateral rectal wall. There may be several possible factors contributing the development of rectal diverticulum in the area after STARR surgery. Firstly, the longitudinal layer of rectal wall tends to be thicker at anterior and posterior locations compared with lateral locations [10]. Secondly, the lateral rectal wall is the location where anterior and posterior suture lines cross one over the other. Thirdly, the lateral part of the rectal wall remained probably outside the staple casing during the second resection. Therefore, complications including dehiscence, perforations, diverticulum or rectal wall exclusion could happen in the weakness area [14]. Frascio $\mathrm{F}$, et al, proposed that diverticulum can be due to an in- complete section of the mucosal band [13]. Nevertheless, in our patient, the anastomotic ring was performed with a fullthickness manual suture and any "posterior staple bridge" was divided with scissors. Indeed, the precise mechanism of rectal diverticulum following STARR procedure need to be further elucidated.

The unexpected complication of rectal diverticulum might be often asymptomatic in the short term, but contribute to recurrence of preoperative symptomatology in the long term. Furthermore, the diverticulum cavity may become inflamed with impacted faeces and progress to abscess formation and even perforation, which similar to "rectal pocket syndrome" has been described after stapled prolassectomy [15]. Surgical reintervention consequently becomes necessary in the event of these serious complications associated with rectal diverticulum. In conclude, risk of iatrogenic rectal diverticulum after STARR surgery should not be underestimated by colorectal surgeons.

\section{Grant}

This work was supported by a grant from the Clinical Re- 
search Fund of Beijing municipal science \& technology commission (No. Z111107058811051).

\section{Conflict of Interest}

The authors declare no conflict of interest.

\section{References}

1. Boccasanta P, Venturi M, Stuto A, Bottini C, Caviglia A, Carriero A, Mascagni D, et al. Stapled transanal rectal resection for outlet obstruction: a prospective, multicenter trial. Dis Colon Rectum. 2004;47(8):1285-1296; discussion 1296-1287.

2. Jayne DG, Schwandner O, Stuto A. Stapled transanal rectal resection for obstructed defecation syndrome: one-year results of the European STARR Registry. Dis Colon Rectum. 2009;52(7):1205-1212; discussion 1212-1204.

3. Schwandner O, Furst A. Assessing the safety, effectiveness, and quality of life after the STARR procedure for obstructed defecation: results of the German STARR registry. Langenbecks Arch Surg. 2010;395(5):505-513.

4. Ding JH, Zhang B, Bi LX, Yin SH, Zhao K. Functional and morphologic outcome after stapled transanal rectal resection for obstructed defecation syndrome. Dis Colon Rectum. 2011;54(4):418-424.

5. Pescatori M, Zbar AP. Reinterventions after complicated or failed STARR procedure. Int J Colorectal Dis. 2009;24(1):87-95.

6. Schwandner O, Stuto A, Jayne D, Lenisa L, Pigot F,
Tuech JJ, Scherer R, et al. Decision-making algorithm for the STARR procedure in obstructed defecation syndrome: position statement of the group of STARR Pioneers. Surg Innov. 2008;15(2):105-109.

7. Weston SD, Schlachter IS. Diverticulum of the rectum. Dis Colon Rectum. 1959;2:458-464.

8. Jayne DG, Finan PJ. Stapled transanal rectal resection for obstructed defaecation and evidence-based practice. Br J Surg. 2005;92(7):793-794.

9. Damron JR, Lieber A, Simmons T. Rectal diverticula. Radiology. 1975;115(3):599-601.

10. Piercy KT, Timaran C, Akin H. Rectal diverticula: report of a case and review of the literature. Dis Colon Rectum. 2002;45(8):1116-1117.

11. Chen CW, Jao SW, Lai HJ, Chiu YC, Kang JC. Isolated rectal diverticulum complicating with rectal prolapse and outlet obstruction: case report. World J Gastroenterol. 2005;11(48):7697-7699.

12. Sciaudone G, Di Stazio C, Guadagni I, Selvaggi F. Rectal diverticulum: a new complication of STARR procedure for obstructed defecation. Tech Coloproctol. 2008;12(1):61-63.

13. Frascio M, Lazzara F, Stabilini C, Fornaro R, De Salvo L, Mandolfino F, Ricci B, et al. Pseudodiverticular defecographic image after STARR procedure for outlet obstruction syndrome. Int J Colorectal Dis. 2009;24(9):1115-1116.

14. De Nardi P, Corsetti M, Staudacher C. Rectal wall exclusion: a new complication after STARR procedure. Colorectal Dis. 2010;12(7):702-703.

15. Pescatori M, Spyrou M, Cobellis L, Bottini C, Tessera G. The rectal pocket syndrome after stapled mucosectomy. Colorectal Dis. 2006;8(9):808-811. 